\title{
A TERCEIRIZAÇÃO E SEU IMPACTO NO BRASIL
}

\author{
Daviane Amorim, Raquel da Silva Santos, Mari Angela Pelegrini \\ Universidade do Oeste Paulista - UNOESTE, curso de Direito, Presidente Prudente, SP.
}

\section{RESUMO}

O objetivo deste trabalho é analisar as consequências fáticas e jurídicas decorrentes da aprovação da terceirização da mão de obra no Brasil, também na atividade-fim da empresa. A possibilidade de contratação de trabalhadores por outra empresa interposta, após a publicação da Lei no 13.429 de 31 de março de 2017 foi o tema central da pesquisa. A antiga restrição, que permitia a terceirização apenas nas atividades intermediárias e as proibia nas atividades ligadas a essência empresarial, exigiu uma pesquisa bibliográfica, pelo método hipotético-dedutivo para verificar as possíveis consequências para aqueles que compõem a relação de emprego. Concluiu-se que é duvidosa a hipótese da suposta elevação da oferta de novas vagas de trabalho e foi comprovado que haverá um aumento do menor poder aquisitivo da classe operária terceirizada doravante, pós-advento permissivo da referida lei.

Palavras Chaves: Terceirização. Flexibilização. Trabalho. Intermediação. Lei.

\section{OUTSOURCING AND ITS IMPACT IN BRAZIL}

\section{ABSTRACT}

The objective of this paper is to analyze the legal and factual consequences of the approval of the outsourcing of labor in Brazil, also in the company's end-activity. The possibility of hiring workers by another company interposed after the publication of Law 13,429 of March 31, 2017 was the central theme of the research. The old restriction, which allowed outsourcing only to intermediary activities and prohibited them in activities related to business essence, required a bibliographic research, using the hypothetical-deductive method to verify the possible consequences for those who make up the employment relationship. It was concluded that the hypothesis of the supposed increase in the supply of new job vacancies is doubtful and it has been proven that there will be an increase in the lower purchasing power of the outsourced working class, since the permissive post-advent of said law.

Keywords: Outsourcing. Flexibilization. Job. Intermediation. Law.

\section{INTRODUÇÃO}

O fenômeno da terceirização passou a ser um tema recorrente nos últimos tempos, mormente após a recente edição da Lei no 13.429 de 31 de março de 2017. Não obstante essa prática já venha sendo utilizada no Brasil há vários anos, ou seja, a intermediação de mão de obra por terceiros, inclusive por meio de empresas organizadas e com contratação direta de trabalhadores, que prestarão serviços para uma empresa contratante, somente agora este instituto foi regulamentado em lei.

Parte da premissa de que, por meio da terceirização, o objetivo maior empresarial é tornar a relação de trabalho mais fácil e menos burocrática, por meio de uma relação trilateral, que tem como membros integrantes: a) a empresa contratante, chamada de "tomadora de serviços"; b) a 
empresa contratada, "terceirizada", ou prestadora de serviços; e c) por último o trabalhador, ou prestador de serviços, comumente denominado de obreiro no meio jurídico trabalhista.

Utilizando-se da pesquisa bibliográfica, principalmente no que concerne ao contexto histórico e econômico do país, a prática da terceirização na atividade-meio (secundária e periférica da empresa), foi confrontada com as contratações diretas e avaliada do ponto de vista de quais serão seus impactos no Brasil.

Tem por objetivo dar ênfase às novidades que a lei $13.429 / 17$ trouxe para os empregadores e empregados brasileiros, para ao final deixar em aberto reflexões que, pela prática empírica da observação do fenômeno, já na atividade-meio, revelava uma precarização das condições de trabalho e diminuição da renda para o trabalhador e a conclusão do trabalho é de que poderá ocorrer de forma mais intensa na terceirização desenfreada na atividade-fim das empresas contratantes.

O objetivo deste artigo é analisar como passará a ser essa relação trilateral agora na atividade fim e quais as possíveis consequências sociais e jurídicas advindas da nova lei regulamentadora da terceirização.

\section{METODOLOGIA}

O respectivo trabalho foi realizado por meio de pesquisas em livros, leis, documentos eletrônicos, e outros meios bibliográficos disponíveis, privilegiando análises dedutivas e hipotéticas, saindo do geral (terceirização como um fenômeno posto e irreversível) para o particular (permissão legal de terceirização de todos os trabalhadores, inclusive na atividade-fim), de forma a confrontar as informações coletadas e instigar o pensamento reflexivo sobre o tema.

\section{DISCUSSÃO}

A terceirização também conhecida como subcontratação, externalização do trabalho, parceria e outros, pode ser entendida com um processo recorrente nas relações de trabalho. Ela possibilita que uma empresa denominada tomadora de serviços contrate outra empresa prestadora de serviços para que esta forneça mão de obra para aquela, ou seja, não existe, a princípio, a contratação de funcionários e sim de uma empresa qualificada para prestar serviços em determinadas atividades.

Usando o exemplo singelo de uma das categorias pioneiras nessa experiência, os vigilantes, contratados para a área de segurança patrimonial, ainda que trabalhem em um banco, classificados para fins do denominado, enquadramento sindical, não como "bancários", ou seja, não são funcionários registrados do próprio banco, eles são funcionários terceirizados e diretamente contratados e registrados por uma empresa de segurança, que presta serviços aos bancos, portanto, vinculados a outro empregador e com outro enquadramento sindical.

Sabe-se que essa intermediação de mão de obra e a necessidade de pagamento para a empresa contratada de valores adicionais por sua administração, faz com que o trabalhador, que ocupará a última posição nesta relação jurídica trilateral, acabe perdendo muitos direitos.

Supostamente os direitos trabalhistas básicos seriam assegurados pelo empregador direto (terceirizado). Mas, a prática tem revelado o contrário, pois, em passado recente, ainda quando era permitida, com base na interpretação dos tribunais do trabalho, a terceirização apenas na atividade-meio, diante da ausência anterior de legislação específica, sonegação reiterada de direitos mínimos.

Interessante pontuar, neste momento, o que se entende por atividade-meio. Delgado, Godinho (2016, p.503) conceitua: 
Atividades-meio são aquelas funções ou tarefas empresariais e laborais que não se ajustam ao núcleo da dinâmica empresarial do tomador de serviços, nem compõem a essência dessa dinâmica ou contribuem para a definição de seu posicionamento no contexto empresarial e econômico mais amplo. São, portanto, atividades periféricas à essência da dinâmica empresarial do tomador de serviços. São, ilustrativamente, as atividades referidas, originalmente, pelo antigo texto da Lei n. 5.645, de 1970: "transporte, conservação, custódia, operação de elevadores, limpeza e outras assemelhadas". São também outras atividades meramente instrumentais, de estrito apoio logístico ao empreendimento (serviço de alimentação aos empregados do estabelecimento, etc.). (DELGADO. 2016, p. 503)

Já a respeito do conceito de atividade-fim Martins (2014, p.130) leciona com precisão cirúrgica ao dizer que "Atividade-fim é a que diz respeito aos objetivos da empresa, incluindo a produção de bens ou serviços, a comercialização etc. É a atividade central da empresa, direta de seu objeto social".

Tendo a exata noção de que a terceirização da atividade-fim empresarial atingirá todo seu objeto social, ou sua atividade central, e que a intermediação de mão de obra, até então, nunca fora visto com bons olhos pela doutrina e jurisprudência, bem por isso tal fenômeno já foi considerado ilícito de acordo com a jurisprudência antes materializada na Súmula 256 do Tribunal Superior do Trabalho (TST).

Não obstante, a crescente intermediação de mão de obra, de forma indiscriminada, exigiu criatividade dos tribunais trabalhistas que resultou na edição da Súmula 331 do TST.

Todavia, avançava a realidade trazendo a propalada necessidade da regulamentação por parte da classe empresarial, que veio no ano de 2017, pela lei citada, causando verdadeira revolução na leitura anterior.

A par da insegurança jurídica alegada pela classe patronal diante da ausência de legislação, o Tribunal Superior do Trabalho praticamente regulamentou a utilização da intermediação de mão de obra, embora apenas por exceção e limitada a atividade-meio.

E tal garantia, ainda que decorrente apenas de interpretação dos tribunais aos inúmeros caos concretos, trazia certa estabilidade e inegável garantia para o trabalhador.

Contudo, segundo alegavam os patrões, a jurisprudência os deixava inseguros com as condenações, inclusive de forma solidária em casos de entendimento de que havia fraude na contratação de serviços por empresas não idôneas, sem capacidade financeira, em sua atividadefim.

Por outro lado, a tentativa de manter a responsabilidade solidária na regulamentação, não vingou e numa manobra ardilosa do congresso nacional (desengavetaram um projeto antigo e colocaram em votação antes arquivada, desprezando outro amplamente discutido pela sociedade).

Assim, mantida a responsabilidade subsidiária, que exige o esgotamento dos bens da empresa terceirizada e seus sócios (no último caso, no chamado incidente de desconsideração da personalidade jurídica), subsiste a insegurança de efetividade no momento da execução trabalhista.

Inegável que, apesar de ser garantida, agora pela lei a responsabilidade subsidiária, antes já reconhecida pela jurisprudência dominante, o trabalhador fica e continuará refém de contratos temporários e precários. 
Não é interessante, constatam os empresários, que criam vagas de emprego e se beneficiam da mão de obra terceirizada, registrar trabalhadores, assinar suas carteiras de trabalho, ser responsável pelos encargos trabalhistas e previdenciários, podendo ter a responsabilidade transferida para terceiros.

Evitam assim, agora com respaldo na lei, firmarem contratos por tempo indeterminado, regra de proteção no direito do trabalho e, por tabela, dividem a responsabilidade nestas contratações, já que a legislação permite que não assumam, sozinhas, todos os riscos da atividade econômica.

Pela experiência na terceirização das atividades periféricas e não em atividade-fim foi forçoso constatar que as empresas terceirizadas repassam ao trabalhador aquilo que entendem ser o mínimo aceitável, de modo que possa justificar a intermediação.

Ocorre que quando, por qualquer motivo, uma crise financeira por exemplo, principalmente num determinado ramo de atividade, recai sobre a tomadora de serviços, num efeito dominó, descartada será a terceirizada. Evidente que o trabalhador ficará desamparado, pois é o mais fraco na cadeia produtiva.

O empregador direto (terceirizado) é, portanto o primeiro a ser descartado e, por tabela, o trabalhador. E esse mesmo trabalhador não tendo, por força de lei, qualquer vínculo jurídico com a tomadora de serviços, para quem efetivamente cedeu sua força de trabalho, caminhará numa inevitável e longa via sacra judicial até atingir o empregador principal na busca de seus sagrados direitos trabalhistas, de natureza alimentar.

Inexistente os requisitos que caracterizam a relação trabalhista, agora por força de lei, em relação à empresa contratante, não lhe restará outra saída.

E a observação simples, empírica, resulta da experiência dos tribunais do trabalho, que se reflete pelo número assustador de reclamações trabalhistas contra empresas terceirizadas, sem solução na fase executiva, o que, de plano, já é prova de que essa forma de contratar não terá um fim positivo, para os trabalhadores, claro.

Muito antes da aprovação da terceirização irrestrita pelo Congresso Nacional, em 22 de março, o Brasil já revelavam as estatísticas: havia no Brasil há dois anos $18,9 \%$ do total de empregados contratados pelo regime da terceirização. Os dados são do Suplemento de Relações de Trabalho e Sindicalização da Pnad 2015 (Pesquisa Nacional por Amostra de Domicílios) ${ }^{1}$

E o que é pior, outros dados, desta feita do Departamento Intersindical de Estatística e Estudos Socioeconômicos (DIEESE), apontam que os salários dos empregados terceirizados são, em média, $25 \%$ mais baixos do que os dos trabalhadores contratados diretamente. Além disso, segundo o mesmo Dieese, os funcionários terceirizados trabalham três (três) horas a mais do que os efetivos, e corre um risco maior de sofrerem acidentes de trabalho.

\section{CONCLUSÃO}

Apesar de ser uma relação simples formada apenas por três componentes, a terceirização causa grande discussão no mundo jurídico, pois é avassaladora sua consequência que anuncia, com a nova lei, o aumento vertiginoso da intermediação de mão de obra.

A terceirização nunca foi alvo de tanta polêmica como atualmente, depois que a Lei no 13.429, de 31 de março de 2017 foi sancionada pelo atual presidente Michel Temer. Antes havia o uso da terceirização de forma arriscada, cuja sinalização de licitude ou não era balizada tão somente pela a súmula 331 do TST, que não tratava tão profundamente sobre o tema, mas permitia o mínimo de segurança à classe trabalhadora, pelo simples fato de impedir, ao menos, a terceirização na atividade vital, central e fim da empresa.

\footnotetext{
${ }^{1}$ Informação divulgada pelo IBGE (Instituto Brasileiro de Geografia e Estatística). 
Do ponto de vista histórico legislativo, pode parecer um grande avanço, pois antes não havia no ordenamento jurídico uma lei específica, no âmbito econômico, temos de um lado benefícios para as grandes empresas e para supostamente para o próprio país, já de outro, para os trabalhadores, maior número de cidadãos destinatários das normas trabalhistas, é evidente o retrocesso, ao argumento de que o desemprego diminuiria.

A precarização das condições de trabalho é um mero reflexo da experiência anterior, na atividade-meio, agora liberada e ampliada para a atividade-fim.

Com o advento dessa nova legislação surgirão vários e novos desafios. A demanda jurídica aumentará devido ao descontentamento dos trabalhadores, que serão despejados aos montes na fila do desemprego a cada fechamento de empresa. Além disso, a responsabilização subsidiária gerará grande desconforto para a efetividade do recebimento das verbas alimentares básicas nas rescisões imotivadas.

O que resta é esperar para que os aplicadores do direito achem a melhor maneira de contornar as adversidades que surgirão a partir de agora.

\section{REFERÊNCIA}

BRASIL, Consolidação das Leis do Trabalho. Decreto-lei, $\mathrm{n}^{\circ}$ 5.452, de 1 de maio de 1943. Das normas gerais de tutela do trabalho. Disponível em: <http://www.planalto.gov.br/ccivil_03/decreto-lei/Del5452.htm>. Acesso em: 7 ago. 2017

BRASIL. Congresso Nacional. Lei $n^{\circ}$. 13429 de 31 de março de 2017. Dispõe sobre o trabalho temporário nas empresas e dá outras providências; e dispõe sobre as relações de trabalho nas empresas de prestação de serviços a terceiros. Diário Oficial da União, Brasília, DF, 31 jan. 2017. Disponível em: < http://www.planalto.gov.br/ccivil_03/_ato2015-2018/2015/lei/l13146.htm>. Acesso em: 08 ago. 2017.

BRASIL. Constituição da República Federativa do Brasil de 05 de outubro de 1988. Diário Oficial da União, Brasília, 05 out. 1988 Disponível em: <http://www.planalto.gov.br/ccivil_03/constituicao/constituicaocompilado.htm >. Acesso em 06 jul. 2017

BRASIL. Tribunal superior do Trabalho. O fato de o empregado não possuir diploma de profissionalização de auxiliar de laboratório não afasta a observância das normas da Lei no 3.999, de 15.12.1961, uma vez comprovada a prestação de serviços na atividade. Disponível em: <http://www3.tst.jus.br/jurisprudencia/Sumulas_com_indice/Sumulas_Ind_301_350.html\#SUM331>. Acesso em: 14 ago. 2017

DELGADO, Mauricio Godinho. Curso de Direito do Trabalho. 15. ed. São Paulo: Ltr, 2016

LADEIRA, Pedro. Dez perguntas para entender o que é a terceirização e como ela afeta sua vida. São Paulo, 23 mar. 2017.2 Disponível em: <https://economia.uol.com.br/noticias/redacao/2017/03/23/dez-perguntas-para-entender-o-quee-terceirizacao-e-como-ela-afeta-sua-vida.htm>. Acesso em: 14 ago. 2017.

MARTINS, Sergio Pinto. Direito do trabalho. 32. ed. São Paulo: Saraiva,2016 
OLIVEIRA, Rodrigo Montenegro de. A terceirização na administração pública: Súmula 331 do TST versus julgamento da ADC 16/DF. Teresina, 20 abr. 2011. Disponível em: <https://jus.com.br/artigos/18933>. Acesso em: 15 ago. 2017. 